\title{
Aspectos Artísticos Da Azulejaria Portuguesa Por Meio Do Design Têxtil E De Superfície Na Moda
}

Matheus Miguel de Souza

Graduado e Mestrando em Têxtil e Moda pela Escola de Artes, Ciências e Humanidades da Universidade de São Paulo - EACH/USP./ ns.souza07@gmail.com

Orcid: 0000-0002-5484-3850/http://lattes.cnpq.br/0163761377107928

Maria Silvia Barros de Held

Doutora em Artes pela Escola de Comunicação e Artes da Universidade de São Paulo - ECA/USP /Silviaheld.usp@gmail.com

Orcid: 0000-0003-4373-4955/http://lattes.cnpq.br/5645756396955777

Enviado 2018-06-30/Aceito 2018-08-15 


\title{
Aspectos Artísticos Da Azulejaria Portuguesa Por Meio Do Design Têxtil E De Superfície Na Moda
}

\author{
RESUMO \\ Este estudo tem como principal objetivo analisar os aspectos \\ artísticos da azulejaria portuguesa como uma das principais \\ fontes de inspiração no desenvolvimento e planejamento de \\ coleções de moda contemporâneas. Especificamente, aborda \\ a arte da azulejaria como sendo um dos mais importantes \\ meios de desenvolvimento do Design Cerâmico e analisa \\ brevemente seu histórico e origens. Analisa também o \\ Design Têxtil, em particular o setor de Estamparia, como \\ área de atuação e desenvolvimento do Design de Superfície, \\ evidenciando a azulejaria, por intermédio do Design \\ Cerâmico, como fonte de inspiração em diversos processos \\ criativos no que diz respeito à produção de novos produtos \\ atrelados ao mercado de Têxtil e Moda na \\ contemporaneidade.
}

Palavras-chave: Azulejaria portuguesa, design têxtil, moda. 


\title{
Artistic Aspects Of Portuguese Tile Through Textile And Surface Design In Fashion
}

\begin{abstract}
This research aims to analyze the artistic aspects of Portuguese tiles as one of the main sources of inspiration in the development and planning of contemporary fashion collections. Specifically, it addresses the art of tile as one of the most important means of developing Ceramic Design and briefly analyzes its history and origins. It also analyzes the Textile Design, in special the textile printing sector, as an area of development of Surface Design, showing the tiles, through the Ceramic Design, as a source of inspiration in several creative processes with regard to the production of new products linked to the Textile and Fashion market in contemporary times.
\end{abstract}

Keywords: Portuguese tile, Textile design, Fashion. 


\section{Introdução}

Diretamente relacionado ao desenvolvimento de novos produtos e atrelado a diferentes materiais e substratos, 0 Design de Superfície encontra-se numa fase de grande expansão no país no que diz respeito à sua consolidação enquanto área de pesquisa, desenvolvimento de projetos e processos criativos no campo do Design ${ }^{1}$. Isso se deve ao fato da concepção abrangente que o termo superfície adquiriu na contemporaneidade, tornando-se passível das mais diversas aplicações e interferências por meio do homem no que diz respeito ao desenvolvimento e inserção de novos produtos em diferentes setores atrelados, direta ou indiretamente, ao Design de Superfície, como é o caso do Design Têxtil e de Estamparia

Design da informação não pode tratar a informação como uma simples coisa a ser economicamente e eficazmente embalada para distribuição [...] design da informação é, na verdade, metaprojeto projeto sobre design, design para ajudar as pessoas a fazer e desfazer as suas próprias informações, seu sentido próprio (RÜTHSCHILLING, 2008, p. 24).

No que concerne às suas diferentes áreas de aplicação, o Design de Superfície encontra na cerâmica ${ }^{2}$ um representante ímpar no que diz respeito às mais variadas formas de desenvolvimento de novos produtos no setor. Assim, é nesse sentido que se pode inserir a azulejaria portuguesa enquanto ramo de pesquisa, aplicação e

1 O desenho industrial (ou design) é uma atividade projetual que consiste em determinar as propriedades formais dos objetos produzidos industrialmente. Por propriedades formais não se entende apenas as características exteriores, senão, sobretudo, as relações funcionais e estruturais que fazem com que um produto tenha uma unidade coerente do ponto de vista, tanto do produtor, como do consumidor. (MALDONADO, apud em BOMFIM, 1998, p. 10).

2 A cerâmica é uma mistura de argila com outras matérias-primas inorgânicas. A denominação "cerâmica" é originada da palavra keramus, nome de um bairro de Atenas, um dos primeiros lugares a utilizar a cerâmica com fim utilitário. Os indícios mostram que a cerâmica, como material utilitário, surgiu no Japão e, aproximadamente entre 26.000 e 5.000 a.C., a habilidade da manufatura das peças deixou o país e se espalhou pela Europa e Ásia. (SILVEIRA, 2008, p. 92). 
desenvolvimento crescente do Design de Superfície com relação à sua aplicabilidade cerâmica.

Herança cultural portuguesa, o azulejo foi inserido no Brasil logo no início da colonização, se desenvolvido, ao que tudo indica através de pesquisas históricas, inicialmente na cultura árabe, sendo posteriormente enraizado e desenvolvido em diversos países da Europa, como é o caso não somente de Portugal, mas também Espanha, Itália e Holanda.

É possível afirmar, assim, que o azulejo tem se tornado um vasto campo de estudo, aplicação e desenvolvimento no que diz respeito ao setor de cerâmica ligado diretamente ao Design de Superfície na contemporaneidade. Soma-se a isso o fato de renomados artistas nacionais terem se utilizado dessa matéria prima, o azulejo, como base para a produção de grandes obras no Brasil, como é o caso de artistas como Athos Bulcão e Oscar Niemeyer, que enxergaram no azulejo um potencial estilístico-criativo e uma rica e importante fonte de criação para o desenvolvimento dos mais variados trabalhos ligados ao setor de arquitetura e urbanismo nacional.

Não somente a azulejaria, mas atualmente diversos outros setores encontram-se diretamente relacionados ao Design de Superfície no que diz respeito às suas mais variadas formas de aplicação e desenvolvimento, como é o caso do Design Têxtil, que se encontra intimamente relacionado à área de estamparia enquanto processo de beneficiamento e embelezamento dos mais variados tecidos. O setor de estamparia em si tem se tornado cada vez mais crescente devido ao aprimoramento das mais variadas técnicas no mercado industrial, especialmente no que diz respeito ao desenvolvimento da estamparia digital na contemporaneidade. 
Diretamente relacionado ao Design de Moda, o Design Têxtil assume, enquanto setor estritamente relacionado ao Design de Superfície, um importante destaque no que concerne à produção e desenvolvimento de novos produtos relacionados ao têxtil e à moda atrelados, diretamente, ao setor de estamparia. Assim, o setor de estamparia se desenvolve, em paralelo ao Design Têxtil e de Superfície, como um importante campo no que diz respeito a novas aplicabilidades e potencialidades no setor de moda e de decoração.

Com características ímpares atreladas ao desenvolvimento de novos produtos, especificamente no setor de moda, o Design Têxtil e de Estamparia se utiliza das mais diversas fontes criativas como inspiração na contemporaneidade. É através disso que se observa um movimento de convergência direta no que diz respeito à azulejaria portuguesa enquanto fonte criativa para os mais diversos trabalhos ligados diretamente à área de moda, por intermédio dos mais diversos estilistas e designers contemporâneos. É por intermédio da estamparia que a azulejaria portuguesa passa a ganhar forma e adquire papel de destaque em diferentes trabalhos criativos ligados à moda através de seu estilo inconfundível e design primoroso no que concerne às suas formas e cores através da indumentária. Nesse sentido, torna-se importante realçar o forte papel comunicacional que a moda assume, direta ou indiretamente, por intermédio não somente de suas formas, cores e volumes, mas principalmente pelas imagens que carrega através de suas estampas, sendo estas, produtos diretos do Design Têxtil e de Estamparia enquanto Design de Superfície.

Assim, o Design de Estamparia assume um lugar de importante destaque, na contemporaneidade, no que diz respeito à representatividade, ressignificação e tradução de 
valores estético-culturais e históricos quando aplicado e trabalhado diretamente no desenvolvimento de novos produtos de moda. Dessa maneira, a moda surge como um importante palco de atuação, aplicação e desenvolvimento do Design Têxtil, por intermédio da estamparia, no que diz respeito à tradução de uma linguagem estética específica, tendo muitas vezes como base as mais diversas fontes de inspiração, como é o caso da azulejaria, importante objeto de estudo e análise do Design Cerâmico e de Superfície. Observa-se, nesse sentido, como o Design de Superfície, além de se relacionar direta ou indiretamente a diferentes áreas e passível de aplicações nos mais variados substratos, também funciona como elo entre os mais diversos processos criativos. Dessa maneira, cria uma cadeia complexa no que diz respeito à produção não somente de valores estéticos aos mais variados produtos, mas também, e principalmente, agrega funcionalidade através de um design inovador e que carrega consigo atribuições histórico-culturais e tradução de valores específicos no que diz respeito a uma determinada cultura ou objeto de estudo.

\section{Histórico e origens do azulejo.}

Azulejo refere-se ao ladrilho cerâmico de superfície regular, quadrada ou poligonal, com uma das faces decorada com esmaltes, destinado, por multiplicação, a ornamentar superfícies parietais ou pavimentares. (SOUZA, 2013). A palavra deriva do árabe, az-zullaiju, que significa pedra lisa ou pedra polida. Alguns etimologistas também vinculam o vocábulo azulejo ao persa lazaward ou mesmo lápis-lazuli ou, ainda, a zallaja, que quer dizer liso ou escorregadio.

É importante salientar que muito antes de sua utilização na Península Ibérica, especialmente em Portugal, o azulejo foi muito utilizado por diversas civilizações e em larga escala 
principalmente pelos árabes. Vestígios arqueológicos acusam sua utilização em regiões como o Egito e a Mesopotâmia, o que demonstra que o azulejo já se apresentava como objeto decorativo e de ornamentação artística muito antes do que se conhece hoje em países como Portugal e Espanha.

Algo parecido com azulejos foi encontrado por arqueólogos nos zigurates, pirâmides, templos e palácios egípcios ou da Mesopotâmia, cujas paredes eram recobertas com baixos-relevos, pinturas e tijolos vidrados. Também os assírios e neobabilônicos tinham o hábito de recobrir as paredes de seus palácios e templos com placas de barro colorido e esmaltado (MORAIS, 1988, p. 126).

Dessa maneira, observa-se que o emprego do azulejo como forma de revestimento cerâmico em paredes, chão e mesmo abóbodas de igrejas e templos remonta desde a cultura muçulmana, penetrando posteriormente em larga escala na Península Ibérica. Salienta-se que a utilização do azulejo, enquanto revestimento cerâmico, sempre esteve relacionada ao embelezamento e ornamentação de espaços onde fora aplicado, além da necessidade de colorir e alegrar:

A aplicação de cerâmica à arquitetura tem suas raízes nas civilizações do Oriente Próximo. Nasce da necessidade de alegrar, com uma nota de policromia, as extensas e monótonas fachadas de tijolo cru dos enormes palácios e templos assírios-caldaicos e persas (ALCÂNTARA, 1997, p. 11).

Foi no século XIX que, por intermédio de campanhas de escavações arqueológicas, conduzidas por grandes nações da Europa e da América, o mundo tomou conhecimento do grandioso e vasto conjunto cerâmico da Avenida Processional da Babilônia (figura 1), datado do século VII a.C., decorada, em sua extensão, com leões em baixorelevo de cerâmica vidrada, tendo seu início na Porta de Ishtar, mostrando touros e dragões alados representados em baixos-relevos, vidrados de amarelo, de tons melados e 
brancos. Além disso, também no século XIX e no que concerne à catalogação de revestimentos cerâmicos, tem-se a divulgação e apresentação, por intermédio de museus, de coleções cerâmicas das ditas civilizações clássicas, com destaque para a cerâmica arquitetônica do legado etrusco, tendo este povo substituído em suas esculturas e baixosrelevos os vidrados brilhantes por englobes avermelhados, cinzentos e negros, sendo esta uma herança da tradição grega. Tais contribuições, além do conhecimento urbanístico das cidades mártires de Pompéia e Herculano, fomentara o gosto da aplicação da cerâmica à arquitetura, que acompanhou outros revivalismos característicos da arquitetura europeia no século XIX. (ALCÂNTARA, 1997). Não tendo participado das escavações do Oriente Próximo, Portugal teve pouco ou quase nenhum acesso a estes resultados. A grande difusão da cerâmica como revestimento oitocentista chegou indiretamente à Península Ibérica, especialmente através de Sevilha onde, a partir daí, desenvolveu-se largamente em diferentes países e, principalmente, em Portugal, assumindo características ímpares e peculiares no que diz respeito à utilização dos azulejos enquanto revestimento cerâmico.

Figura 1: Portões de Ishtar, Avenida Processual da Babilônia.

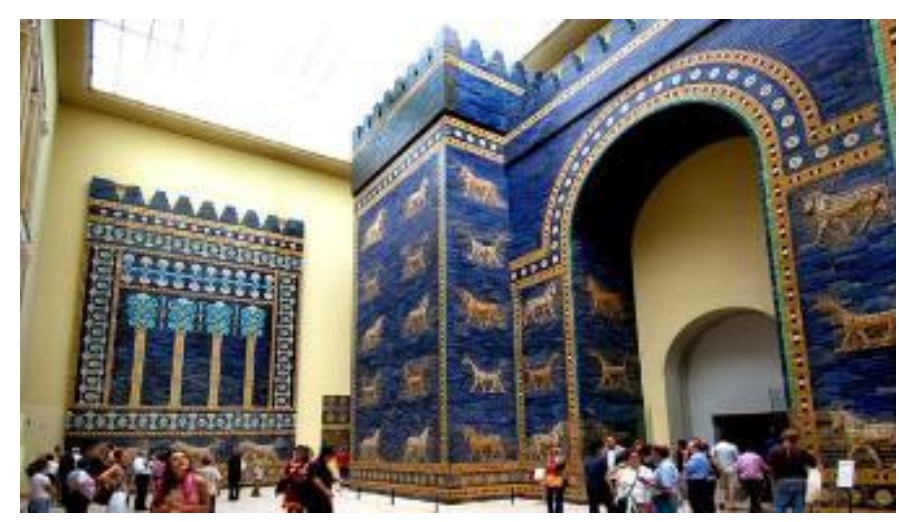

Fonte: http://www.bbc.com/culture/story/20150302ancient-babylons-greatest-wonder (Acesso em 20 de fevereiro de 2018). 


\section{Design de superfície: conceito e aplicações.}

O Design de Superfície vive hoje no Brasil um momento de extraordinária ampliação, ao mesmo tempo em que se consolida como área de atuação profissional e de conhecimento específico, muito embora ainda seja pouco difundido ou mesmo abordado em suas várias formas de aplicação no mundo do design.

No que diz respeito às suas diferentes formas de atuação e aplicação, é necessário que se compreenda, primeiramente, o significado do termo Design de Superfície, para que se possa categorizar e exemplificar uma diversificada gama de áreas nas quais, direta ou indiretamente e, mesmo sobre as diferentes maneiras, o profissional dessa área atua no cenário brasileiro.

Segundo Evelise Anicet do Núcleo de Design de Superfície (NDS) da Universidade Federal do Rio Grande do Sul (UFRGS) pode-se definir o Design de Superfície como:

(...) uma atividade criativa e técnica que se ocupa com a criação e desenvolvimento de qualidades estéticas, funcionas e estruturais, projetadas especificamente para constituição e/ou tratamentos de superfícies, adequadas ao contexto sociocultural e às diferentes necessidades e processos produtivos (RÜTHSCHILLING, 2008, p. 23).

Ou ainda, segundo a designer de superfície Renata Rubim, é "todo o projeto elaborado por um designer, no que diz respeito ao tratamento e cor utilizados em uma superfície, industrial ou não" (RUBIM, 2010, p. 21).

Dessa forma, é possível compreender que o Design de Superfície, enquanto campo de aplicação está intrinsecamente ligado a diferentes formas, matérias e texturas. Compreende-se também que sua interferência tende a modificar e criar novos aspectos visuais e táteis como forma de valorizar e proporcionar uma ampla cadeia 
de produtos e materiais, não somente no que diz respeito ao mercado de consumo (produtos têxteis e cerâmicos), mas também ao cotidiano como um todo (painéis, paredes, calçadas e avenidas em geral).

Contudo, é necessário tomar nota que o termo utilizado, Design de Superfície, ainda é praticamente desconhecido em todo o Brasil. Segundo Renata Rubim:

(...) essa designação é amplamente utilizada nos Estados Unidos (...) e foi introduzida por mim no Brasil na década de 1980 - quando retornei de lá após um período de estudos -, por considerá-la a melhor definição existente (RUBIM, 2010, p. 21).

No que diz respeito às origens do Design de Superfície no Brasil, pode-se dizer que ele surge como:

(...) um campo de conhecimento e de prática profissional autônomo, no Rio Grande do Sul. (...) A referência mais concreta encontrada é a fundação da 'Surface Design Association - DAS', em 1977, nos Estados Unidos da América, onde provavelmente essa associação de artistas têxteis tenha sido responsável pela criação da expressão e uso oficial da nomenclatura surface design (RÜTHSCHILLING, 2008, p. 11).

Dentro das aplicações que envolvem o Design de Superfície, Rüthschiling (2008) mostra como há diversas formas de aplicações e usos do mesmo foram executadas no decorrer das décadas.

As civilizações antigas desenvolveram o gosto pela decoração de superfícies em geral, principalmente nos utensílios domésticos, espaços arquitetônicos e artefatos têxteis. Pode-se dizer que a tecelagem e a cerâmica, assim como, posteriormente, a estamparia e a azulejaria, com sua linguagem visual, carregam o embrião do que chamamos de design de superfície (RÜTHSCHILLING, 2008, p. 16).

Miriam Levinbook (2008), a esse respeito, complementa: 
Por ser uma área relativamente nova, o Design de Superfície no Brasil oferece aos pesquisadores em design um fértil caminho de estudo e reflexão. Em meio às pesquisas a respeito dos conceitos que envolvem o Design de Superfície, encontram-se referências que abrangem superfícies como papel, vidro, pisos em geral, cerâmica e têxtil (LEVINBOOK, apud em PIRES, 2008, p. 371).

Pode-se dizer que o Design de Superfície está intimamente relacionado a diversas áreas de atuação e desenvolvimento no Brasil, uma vez que dialoga com os materiais e superfícies nas quais será aplicado e desenvolvido um projeto como modo de transformá-lo e atribuir-lhe um maior valor estético, além da interferência desses materiais. De acordo com Rüthschiling (2008):

O design de superfície - DS -, na forma como foi estruturado no Brasil, abrange várias especialidades. Por exemplo, pode-se dizer que o design têxtil, design cerâmico, design de estamparia, dentre outros, estão contidos dentro do campo do design de superfície. (...) Nesse contexto, o design de superfície ocupa espaço singular dentro da área do design, que por sua vez possui elementos, sintaxe da linguagem visual e ferramentas projetivas próprias. Abraça campo de conhecimento capaz de fundamentar e qualificar projetos de tratamentos de superfícies do ambiente social humano (RÜTHSCHILLING, 2008, p. 25).

Muito embora o Design de Superfície esteja relacionado ao design têxtil e de estamparia no Brasil, ele engloba muitos outros aspectos e formas de aplicação no que tange a aspectos decorativos e inovadores em desenvolvimento no mercado de consumo em geral. Dentre os diferentes ramos de segmentação de atuação e aplicação do designer de superfície, pode-se citar:

Papelaria: está ligado à área de criação de estampas para papéis de embrulho, embalagens, produtos descartáveis (guardanapos, pratos e bandejas de papel), além de materiais para escritório como capas de agendas e cadernos, blocos de papéis, etc. 
Têxtil: área que abrange produtos constituídos de fibras e todos os tipos de tecidos e não tecidos, contribuindo para seu acabamento e embelezamento finais, sendo uma das maiores áreas de atuação do design de superfície.

Cerâmica: área de atuação que compreende diversas formas de materiais como pisos, paredes, azulejos e lajotas, representando um importante campo de aplicação do design de superfície.

Materiais Sintéticos: há uma constante inovação por parte das indústrias na produção de novos materiais sintéticos para revestimentos variados, sendo o mais conhecido deles a Fórmica (plástico laminado produzido pela Formica Corporation ${ }^{\circledR}$ ). Hoje apresenta modos de customização, oferecendo aos clientes a possibilidade de utilização de estampas e texturas exclusivas (RÜTHSCHILLING, 2008).

Embora estes sejam bons exemplos dos diversos campos de atuação dos designers de superfície, há também milhares de meios e técnicas de aplicação e desenvolvimento de projetos a serem executados em diferentes materiais ainda inexplorados.

Segundo Renata Rubim (2010):

As aplicações possíveis ao Design de Superfície são inúmeras. As mais comuns são: design têxtil, design cerâmico, design de porcelana, plástico e papel. Temos ainda outras superfícies que podem receber projetos interessantes, tais como vidros e emborrachados, pois ainda não foram suficientemente explorados (RUBIM, 2010, p. 47).

Além desses aspectos, é preciso pensar o Design de Superfície muito além somente da estampagem e da elaboração de projetos que viabilizem apenas um determinado plano como forma de interferência visual. Com a inserção constante de novas tecnologias no mercado observa-se uma intensa produção que transita pelos mais 
diferentes meios, suportes, mídias e escalas. Surgem novas aplicações em diferentes produtos, revelando um panorama amplo, variado, inovador e em expansão (RÜTHSCHILLING, 2008).

\section{Design têxtil como design de superfície}

No que diz respeito ao Design de Superfície e suas áreas de atuação, pode-se destacar o setor têxtil como uma das mais amplas e crescentes no país, principalmente graças aos constantes impulsos da Moda pela busca do novo, da realização e da conquista de novas formas, além de designs cada vez mais rebuscados e inusitados. De acordo com Lipovetsky (2009):

(...) na moda, o mínimo e o máximo, o sóbrio e a lantejoula, a voga e a reação que provoca são da mesma essência, quaisquer que sejam os efeitos estéticos opostos que suscitem: sempre se trata do império do capricho, sustentado pela mesma paixão de novidade e de alarde (LIPOVETSKY, 2009, p. 40).

Através dessa ótica podem-se estabelecer relações entre o Design de Superfície e suas aplicações ligadas ao campo da Moda, tanto como forma estética quanto na síntese de linguagem visual, promovendo relações conjuntivas entre a roupa e o corpo, principalmente no que diz respeito a traços de identidade do sujeito em diferentes aspectos. O Design de Superfície é responsável, em sua grande maioria, pela união desses aspectos no que diz respeito ao setor têxtil: o da pesquisa e da confecção de novas formas aplicadas aos têxteis (estamparia, principalmente) e a disponibilização de produtos cada vez mais diferenciados e exclusivos.

Em relação ao Design Têxtil como ramificação do Design de Superfície, Renata Rubim (2010) enuncia: 
No setor têxtil, por exemplo, a riqueza de aplicações é fascinante. Temos os estampados, os tecidos (ou tramados), malharias, tricôs, bordados. No caso dos estampados, há uma gama enorme de possibilidades, que vai desde um simples xadrezinho, até os caríssimos e requintados florais utilizados para ornamentação de ambientes luxuosos (RUBIM, 2010, p. 48).

No que concerne ao Design Têxtil, uma de suas principais potencialidades e que se encontra intimamente relacionada ao Design de Superfície é o setor de estamparia - "técnica que designa, de maneira genérica, diferentes procedimentos que têm como finalidade produzir desenhos coloridos ou monocromáticos na superfície de um tecido, como se fosse uma pintura localizada que se repete ao longo da metragem da peça e aplicada no seu lado direito" (YAMANE, 2008, p. 19). De maneira genérica "a finalidade da verdadeira estamparia é a de tornar o tecido mais atraente e chamar a atenção de um possível usuário e, claro, a de renovar a moda permanentemente e conquistar novas posições no mercado consumidor" (CHATAIGNIER, 2006, p. 81).

Os diferentes estilos de estamparia têxtil (dentre eles os florais, geométricos, históricos, irregulares, étnicos e artísticos, dentre outros) estão intimamente ligados aos conceitos de composição e harmonia visual, promovidos principalmente pela organização e articulação dos módulos (unidade de padronagem e menor área que inclui os elementos visuais constituintes do desenho), o que acaba por gerar um padrão de repetição ou o chamado rapport (sistema de repetição promovido pelas diferentes formas de posicionamento dos módulos).

Em relação à elaboração de projetos ligados ao setor têxtil em geral, não somente o aspecto visual e tátil (conforto) deve ser de conhecimento do Design de Superfície, mas também e principalmente aspectos culturais e histórico-sociais. "A influência sociocultural é um fator que define com precisão os motivos estampados nos tecidos, 
assim como os aspectos relacionados à etnia, costumes e tradições" (CHATAIGNIER, 2006, p. 81), como é o caso da influência da azulejaria e do Design Cerâmico aplicados à moda.

Hoje, constituindo um dos principais setores do Design de Superfície, o Design Cerâmico, especialmente atrelado aos azulejos em geral, tem ganhado também cada vez mais espaço no que diz respeito ao Design Têxtil, especialmente o de Estamparia, como fonte de inspiração em diferentes criações de diversos estilistas, tanto nacionais quanto internacionais. Tem-se hoje um olhar mais primoroso quanto às produções no ramo da azulejaria enquanto Design de Superfície, a ponto de muitas produções passarem a fazer parte de grandes nomes da moda através do setor de Estamparia Têxtil, apropriando-se, direta ou indiretamente, do Design Cerâmico em diferentes processos criativos no que tange à produção de coleções de vestuário. Assim, torna-se interessante analisar como diferentes áreas do Design de Superfície se complementam no que diz respeito à criação e desenvolvimento de produtos em diferentes áreas, no caso, a produção de coleções de moda por intermédio do Design Cerâmico através do Design Têxtil e de Estamparia.

Ainda em aspectos relacionados ao Design Têxtil, assim como no Design de Superfície, evidenciam-se novos aprimoramentos em relação ao objeto principal explorado: o têxtil. Se para o Design de Superfície os objetos de atuação ganham formas cada vez mais complexas e simbólicas na atualidade, para o Design Têxtil as fronteiras entre corpo e interação com a indumentária não têm definição.

No campo do Design Têxtil podemos citar os tecidos inteligentes: "construções realizadas pela engenharia têxtil e pela indústria bioquímica" (AVELAR, 2009, p. 143). As variadas características às quais estes tecidos estão relacionados são às funções que motivaram sua criação: 
proteção, facilidade no cuidado, capacidade de respiração, conforto, durabilidade, resistência, resistência à lavagem e ao vento; com aplicações desde a área esportiva à médicohospitalar.

Pode-se evidenciar, assim, além de uma complementação no que se refere ao Design de Superfície e aos segmentos do design têxtil (principalmente a estamparia), um crescente desenvolvimento técnico-informacional de ambos os lados, de forma a ampliar as fronteiras ainda existentes no que diz respeito ao design e à elaboração de projetos, tanto em relação aos campos de atuação da moda quanto do Design de Superfície.

\section{Design têxtil: inspiração e criatividade na moda por meio do design de superfície}

Torna-se importante evidenciar, aqui, a convergência direta entre o Design Têxtil enquanto ramificação direta do Design de Superfície aplicado à moda, direta ou indiretamente, no que diz respeito à produção e ao desenvolvimento de novos produtos não somente na área de estamparia, mas também ao desenvolvimento de novos tecidos, tingimento e beneficiamento, etc. Nesse aspecto, é de fundamental importância a criatividade e os diferentes processos criativos no que diz respeito ao desenvolvimento de produtos de moda enquanto setor diretamente ligado ao Design Têxtil. Observa-se, portanto, que a moda, num sentido mais amplo, é um importante mecanismo de expressão e produção cultural, refletindo costumes e valores de uma determinada sociedade, além de permitir a reflexão, a criação, a participação e integração de costumes e crenças, possibilitando, assim, a formação da identidade social do indivíduo. Ainda nesse sentido, "a moda não é só 
questão de consumo, mas também de identidade. Ser não é ter, mas parecer". (LOPES, 2000, p. 155).

Em relação ao trabalho criativo, o mesmo pode ser definido como a "ação em que o homem se reproduz, em que se cria novas necessidades, é o espaço onde tudo se renova". (GUIMARÃES, 2000, p. 29). Dessa maneira, o designer ou mesmo estilista, por intermédio do Design Têxtil aplicado especificamente à moda, tem como uma de suas funções definir, através de diferentes processos criativos, a especificidade de sua coleção ou de seu projeto, seu público alvo, atrelando exclusividade e inovação a seu trabalho, de maneira a atender as demandas produtivas do mercado, tendo em vista a resolução de problemas no que diz respeito ao processo de criação e inovação para além das demandas já previstas.

Neste sentido, e no que concerne à criatividade em diferentes processos criativos, especialmente através da moda enquanto área de criação e desenvolvimento principal do Design Têxtil e de estamparia, é que se pode identificar as inter-relações entre diferentes outras áreas no que diz respeito à inspiração para o desenvolvimento de novos produtos direta ou indiretamente ligados ao Design de Superfície através da moda. No que diz respeito ao processo criativo, com relação às diferentes áreas do Design Têxtil, em especial ao setor ligado à estamparia como Design de Superfície, é necessário que haja fontes de pesquisa e de inspiração como embasamento para a produção dos artigos finais, haja vista a necessidade da exclusividade no mercado da estamparia têxtil. Assim, além de conhecimentos técnicos sobre tecidos, fios e processos, o designer têxtil necessita realizar muita pesquisa de mercado para o desenvolvimento de novos produtos têxteis (LASCHUK, 2009). Tais pesquisas podem ser realizadas de diferentes maneiras, como visitas a 
feiras têxteis, desfiles nacionais e internacionais, além de museus.

As fontes de inspiração no processo de criação do designer têxtil podem ter origem em diferentes lugares, como o próprio resultado das pesquisas que já foram desenvolvidas envolvendo tecidos de diferentes épocas. Assim, é possível o estudo de diversos estilos e épocas, além da utilização de diferentes estruturas e materiais. Alguns dos estilos se tornaram clássicos no setor de estamparia como os listrados, florais e poás. Além disso, pode-se dizer que as diferentes correntes artísticas encontradas ao longo dos anos também influenciaram o Design Têxtil, em especial o setor de estamparia têxtil. Talvez um dos casos mais conhecidos seja o do movimento de artes decorativas e arquitetura chamado Art Nouveau, ocorrido em fins do século $X I X$ e início do século $X X$, influenciando a história da estamparia com suas formas orgânicas, linhas sinuosas e formas florais com inspiração diretamente da natureza. Além desse, o movimento Art Deco também marcou presença na estamparia têxtil com suas linhas geométricas, tendência oposta ao Art Nouveau (figura 2). 
Figura 2: Gucci. Primavera/Verão 2014. Exemplo de estampas ao estilo Art Nouveau.

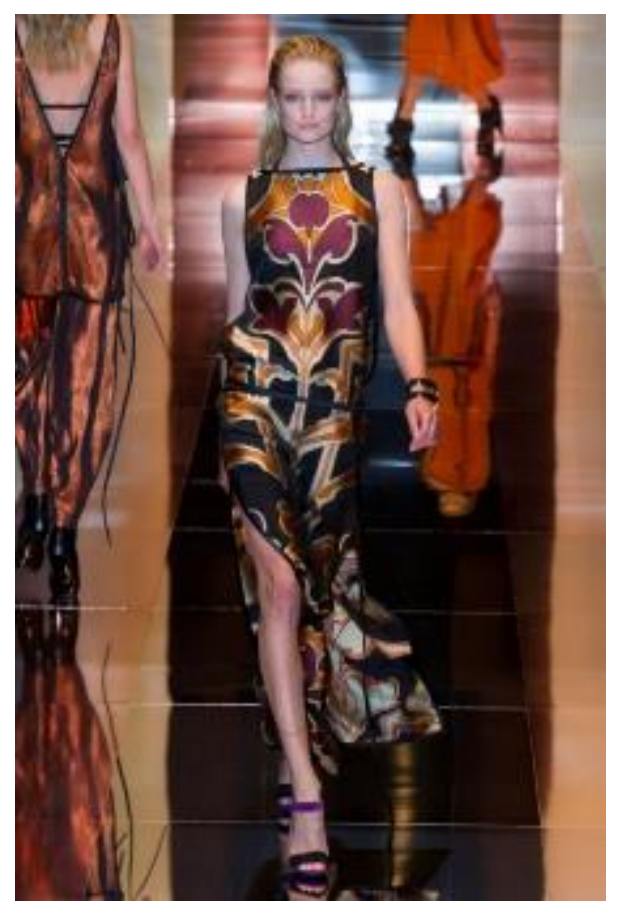

Fonte: http://ffw.uol.com.br/desfiles/milao/verao-2014rtw/gucci/805856/colecao/16/ (Acesso em 24 de fevereiro de 2018).

Ainda no que diz respeito às fontes de inspiração em diferentes processos criativos atrelados ao Design Têxtil e, direta ou indiretamente à moda, pode-se citar a própria arte como sendo uma das principais fontes em termos de referência para o desenvolvimento de novos produtos no mercado. Segundo Mônica Moura, apud em Pires (2008):

A arte tem servido como fonte de pesquisa e referência para a criação e o desenvolvimento de projetos e produtos na esfera da moda ou do design. Por sua vez, vários artistas na história da arte desenvolveram objetos de moda ou de design. Talvez tenham utilizado o campo do design ou da moda como referência ou foram despertados pelo objeto utilitário e de uso cotidiano para a criação de obras artísticas. Estes fatos não ocorrem apenas na contemporaneidade, e sim desde o princípio dos grupos e corporações que deram origem ao design. Pelo menos aqueles de que se tem notícia até hoje e já foram historiados (MOURA, apud em PIRES, 2008, p. 45). 
Paralelamente à arte enquanto referência para novos modelos de produtos no mercado de moda ou design, sejam eles através do Design Têxtil ou de Superfície, outra grande fonte de inspiração e convergência de conteúdos entre esses setores tem sido também a arquitetura, importante modelo de referências no que diz respeito a formas, volumes, cores e texturas, as quais têm se incorporado através de diferentes processos criativos e marcado presença, seja de maneira direta ou não, em novos produtos do design e da moda (figura 3).

Figura 3: Balenciaga foi um dos principais estilistas a levar em consideração a arquitetura como fonte de inspiração em seus trabalhos, muitos deles marcados por linhas retas e tecidos mais rígidos especialmente em peças de alfaiataria. Era considerado o "arquiteto das roupas".

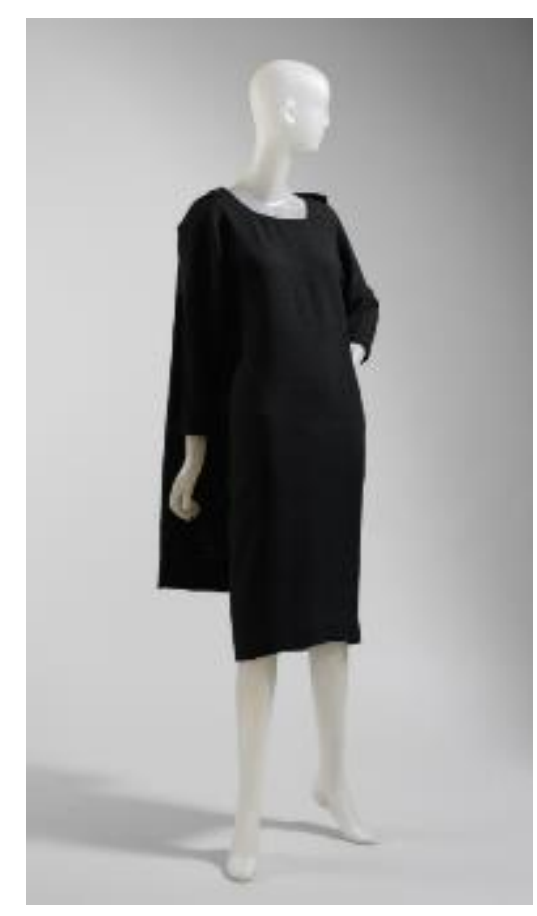

Fonte: https://www.metmuseum.org/toah/works-ofart/1976.124.7a,b/ 9Acesso em 24 de fevereiro de 2018).

Seja através da arte ou mesmo da arquitetura, atualmente é possível verificar como não somente estas, mas diversas outras fontes de inspiração e criatividade vêm sendo incorporadas, direta ou indiretamente, ao trabalho de 
diversos designers no que diz respeito ao desenvolvimento de produtos atrelados ao Design Têxtil e de Moda enquanto Design de Superfície, no Brasil e no mundo. Com isso, são vários os exemplos que podem ser citados em se tratando das mais distintas criações no campo do Design de Têxtil e Moda que tiveram, especialmente na arte e na arquitetura, sua base criativa e de inspiração para a produção de novos artigos no mercado atual (figura 4).

Figura 4: Vestido Mondrian, de Yves Saint Laurent, com base na composição Red Blue Yellow, de Piet Mondrian. 1965.

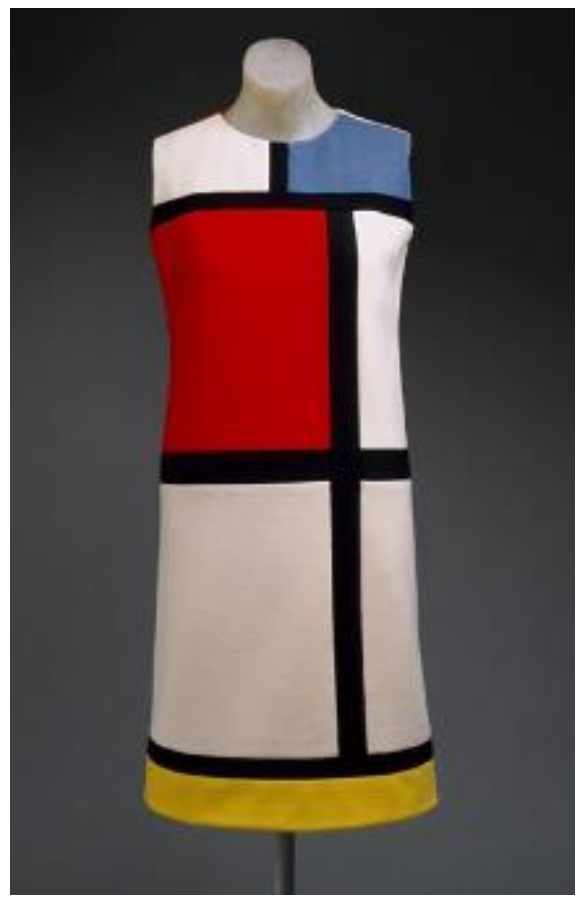

Fonte: http://lifestyle.publico.pt/noticias/297631_vestidoysl-inspirado-em-mondrian-vendido-por-35-mil-euros (Acesso em 24 de fevereiro de 2018).

\section{AZULEIJARIA PORTUGUESA: POSSIBILIDADES NA MODA CONTEMPORÂNEA,}

O Design de Superfície encontra-se ligado a diferentes setores na atualidade, mantendo uma relação complexa com as mais diferentes áreas no que diz respeito à promoção de valores estético-funcionais nos projetos onde atua direta ou indiretamente. Um dos setores mais importantes ligados ao 
Design de Superfície, na contemporaneidade, tem sido o setor de estamparia, relacionado diretamente ao Design Têxtil, que atua diretamente no desenvolvimento de produtos de moda, vestuário, decoração e têxteis em geral no que diz respeito às suas mais variadas formas de aplicação e desenvolvimento.

Através do Design Têxtil e da Estamparia, a moda tem se beneficiado de constantes avanços no que diz respeito não somente à sua parte estética, aquela ligada diretamente ao design de produto, cores, formas e texturas; mas também e principalmente do avanço tecnológico no que diz respeito ao desenvolvimento de novas fibras, fios e tecidos inteligentes, mais resistentes e funcionais, frutos de pesquisas recentemente ligadas ao setor de Design têxtil e de Superfície aplicados à moda.

No que diz respeito a seus valores estéticos, estes ligados diretamente ao design de produto, pode-se afirmar que a estamparia é um dos principais elos de conjunção e convergência direta entre arte e moda. Assim, é através da estamparia têxtil que se pode promover a criação de um design estético diferenciado, criativo e inovador atrelado ao desenvolvimento de produto de moda enquanto ramificação do Design Têxtil.

Uma das formas de presentificação da arte na moda ou
no design ocorre por meio das estampas e padronagens
de tecidos, pelo desenvolvimento de peças ou
complementos do vestuário e da casa. Esses objetos de
moda tanto podem reproduzir detalhes principais das
obras de arte como podem se desenvolver a partir das
referências de um período, estilo ou movimento de arte,
ou ainda, de um determinado artista (MOURA apud
PIRES, 2008, p. 49).

Não somente a arte, mas outras diferentes áreas encontram-se atreladas à moda no que diz respeito ao design e desenvolvimento de produtos inovadores. Assim é o caso da arquitetura, que na moda encontra um elo e 
convergência direta como fonte de inspiração em diferentes processos criativos na contemporaneidade, estreitando as relações entre esses dois universos no que diz respeito à produção e desenvolvimento de produtos de moda com design elaborado e inovador.

\begin{abstract}
Assim como a arte, o design, a arquitetura e o urbanismo são agentes de um fluxo de informação contínua e se apropriam da moda como interlocutora. Pela possibilidade de transitar em todos os lugares e entre as pessoas, as peças do vestuário se tornaram um importante veículo de comunicação. Isso por seu design, suas mensagens 'grafitadas' ou mesmo através das peças artisticamente produzidas, como os vestidos da Maison Dior, que visavam divulgar a arte de Mondrian (MELLO, apud em PIRES, 2008, p. 82).
\end{abstract}

Dessa maneira, a moda assume um importante lugar na contemporaneidade no que diz respeito à comunicação, seja através do design de produto ou até mesmo (e principalmente) através do design de estamparia, uma vez que é por intermédio da estampa, enquanto vetor que agrega valor estético ao produto de moda, que a roupa também comunica diferentes mensagens e cria os mais diversos elos de ligação, sejam eles diretos ou não, com outras áreas do design, como é caso da arquitetura, enquanto suporte criativo atrelado à moda em diferentes projetos.

Pensar a comunicação em suas relações sociais e na sua relação com a moda, difusão, comercialização e adequação de produtos, quando inseridos como valor de mercado e bens de consumo, nos faz refletir sobre questões históricas e estéticas, do desenvolvimento criativo, do desejo de informação e de significação dos objetos produzidos pela moda, de seu valor cultural e de mercado com diferentes abrangências que dizem respeito ao âmbito pessoal, social e ultimamente, também, aos valores globalizados e à rapidez na difusão, mutação e propagação desses valores (CASTILHO, MARTINS, 2005, p. 27). 
É nesse âmbito de comunicação, ligado ao desenvolvimento de produtos de moda e diretamente ligado ao setor de estamparia, que a azulejaria portuguesa assume um papel estético-funcional enquanto inspiração em diferentes processos criativos no que diz respeito à moda e, por conseguinte, diretamente ao design de estamparia. Associada ao setor de arquitetura, a azulejaria portuguesa encontra, assim, um lugar de destaque na moda contemporânea no que diz respeito ao desenvolvimento de produtos através do Design Têxtil e de estamparia.

Nesse âmbito, é importante se ater à definição do conceito "moda" para que se possa fazer uma correlação entre o termo e o desenvolvimento de produtos, do setor de estamparia, tendo como referencial estético-criativo a azulejaria portuguesa. Nesse sentido, Lipovetsky (2009) afirma:

(...) Recolocada na imensa duração da vida das sociedades, a moda não pode ser identificada à simples manifestação das paixões vaidosas e distintivas; ela se torna uma instituição excepcional, altamente problemática, uma realidade sócio histórica característica do Ocidente e da própria modernidade. Desse ponto de vista, a moda é menos signo das ambições de classes do que saída do mundo da tradição, é um desses espelhos onde se torna visível aquilo que faz nosso destino histórico mais singular: a negação do poder imemorial do passado tradicional, a febre moderna das novidades, a aceleração do presente social (LIPOVETSKY, 2009, p. $10-11$ ).

A moda definida enquanto busca constante pelo novo e negação do passado tradicional, como afirma Lipovetsky (2009), é possível verificar que a azulejaria portuguesa, enquanto suporte criativo atrelado diretamente ao Design Têxtil e de estamparia, no que concerne ao desenvolvimento de produtos de moda, representa um certo paradoxo, uma vez que se a moda tem como objetivo a busca incessante pelo novo, negando seu passado alicerçado na tradição, então ela mesma, a moda, busca, através do passado, 
referenciais históricos, estéticos e imagéticos como base para seu desenvolvimento criativo, como é o caso da azulejaria portuguesa. Soma-se a isso o fato de Lipovetsky (2009) afirmar que, de fato, a moda consumada vive de paradoxos, de maneira que é possível, então, presumir que seu ciclo constante e acelerado, na contemporaneidade, afirma e realça a permanência da história, seus valores e sua presença nas suas mais variadas formas, como é o caso da azulejaria portuguesa, representante ímpar da cultura árabe enraizada em Portugal, hoje representante máxima de uma cultura histórico-social de um país.

(...) A moda consuma vive de paradoxos: sua inconstância favorece a constância; suas loucuras, o espírito de tolerância; seu mimetismo, o individualismo; sua frivolidade, o respeito pelos direitos do homem. No filme acelerado da história moderna, começa-se a verificar que, dentre todos os roteiros, 0 da Moda é o menos pior (LIPOVETSKY, 2009, p. 21).

Além da azulejaria portuguesa, é possível também observar como, direta ou indiretamente, diversos outros acontecimentos, períodos ou obras, ligados diretamente ao passado histórico da humanidade, tem servido de base para a criação e o desenvolvimento de produtos de moda, em especial atrelado ao setor de estamparia enquanto Design de Superfície. Mônica Moura (apud PIRES, 2008) afirma:

Outra forma de estabelecer estreita relação entre a arte a moda ocorre quando um determinado período histórico-artístico torna-se referência para a produção em moda. O Renascimento italiano já foi fonte de pesquisa para diversos designers de moda, entre eles, Christian Lacroix, que, na sua coleção outono-inverno 2006/2007, associa as imagens complexas, as cores e os ornamentos do período, estabelecendo uma leitura contemporânea do Renascimento no universo da moda (MOURA apud em PIRES, 2008, p. 57). 
Interagindo direta ou indiretamente com outras áreas, especificamente a azulejaria portuguesa enquanto estritamente relacionada ao setor de arquitetura, a moda então busca promover um diálogo construtivo de maneira a buscar referenciais históricos, por meio da azulejaria, de maneira a criar um repertório estético e imagético que serve de base para o desenvolvimento de novos produtos no mercado, estes atrelados diretamente ao setor de Design Têxtil e de Superfície através da estamparia. A partir disso, pode-se afirmar, então, que através da busca no passado histórico, no que diz respeito à moda e o desenvolvimento de produtos atrelados ao Design Têxtil e de Superfície, existe uma relação direta entre produto e resgate históricocultural que a moda promove, direta ou indiretamente, através de suas criações nas mais variadas formas na contemporaneidade. É através da moda, especificamente através do setor de estamparia, que existe uma promoção de valores estético-culturais e históricos resgatados e novamente introduzidos e reinseridos na contemporaneidade, através de diferentes designers. Iniciase então um diálogo entre diferentes áreas, de modo a promover um resgate de valores não somente históricos, mas principalmente estéticos no que diz respeito ao desenvolvimento de produtos de moda tendo como base criativa o passado histórico da humanidade por intermédio da azulejaria portuguesa.

Pode-se afirmar, portanto, que 'as modas' são o reflexo de um tempo, expressando uma cultura, por meio do design, da arquitetura e do urbanismo, ou ainda, da sociedade e da arte. Fenomenalmente, transcende os próprios conceitos e contamina outras áreas de conhecimento, criando uma geometria transversal e interagindo com as mais diversas disciplinas do saber (MELLO, apud em PIRES, 2008, p. 92). 
Figura 6: Dolce and Gabbana. Coleção Alta Moda, outono de 2014. Ilha de Capri.

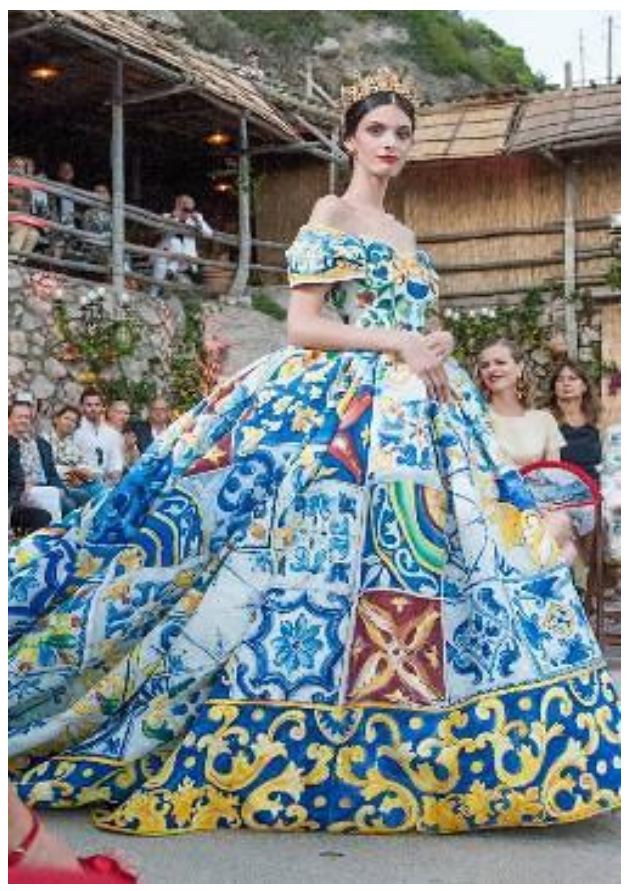

Fonte: https://senatus.net/album/image/126621/\#photo (Acesso em 02 de março de 2018).

Figura 7: Dolce and Gabbana. Coleção I Love Maiolica, outono-inverno 2018/19.

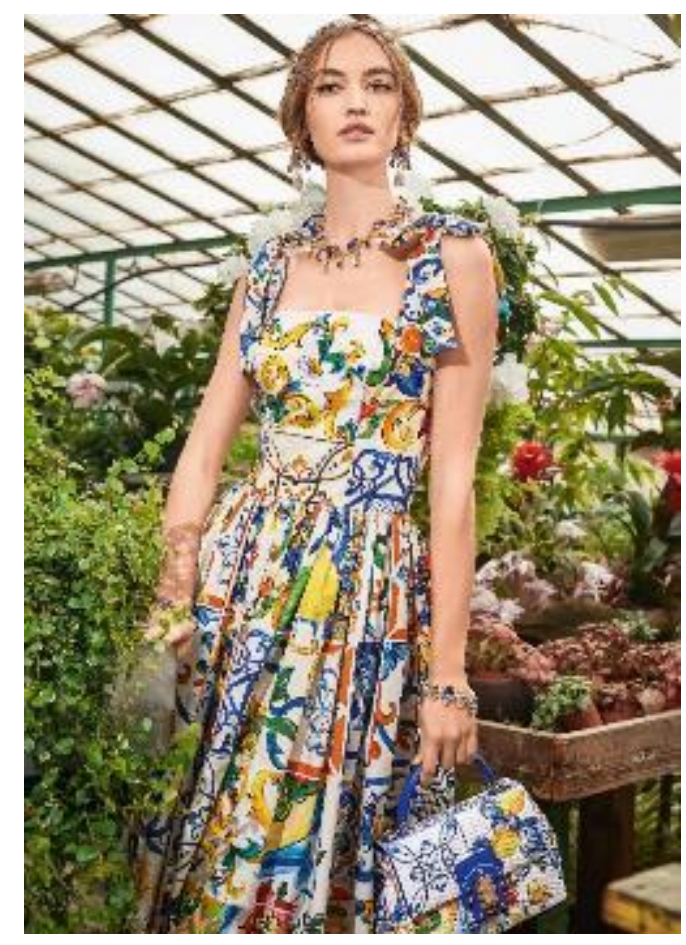

Fonte: https://store.dolcegabbana.com/en/i-love-maiolicacollection/?HP_BAN=BAN2B_180625_MAIOLICA_W (Acesso em $28 \mathrm{de}$ junho de 2018). 


\section{CONSIDERAÇÕES FINAIS}

No que diz respeito aos processos criativos relacionados diretamente ao desenvolvimento de artigos exclusivos ligados ao Design Têxtil e de Estamparia, é possível citar uma infinidade de fontes que servem como inspiração e base para a criação para diferentes designers. É nesse contexto que a arte da azulejaria portuguesa surge como foco principal no que diz respeito à uma valiosa fonte de inspiração diretamente relacionada a diferentes processos criativos no que concerne à produção e desenvolvimento de novos produtos no mercado de moda.

Diretamente relacionado ao Design de Superfície enquanto aplicabilidade cerâmica e de revestimento decorativo, a azulejaria portuguesa tem se apresentado, na contemporaneidade, como uma rica e importante fonte de inspiração para diferentes designers que, por intermédio da estamparia têxtil, têm desenvolvido criações exclusivas no campo da moda.

Torna-se evidente, assim, o caráter holístico e complexo que o Design de Superfície mantém, na contemporaneidade, ao se relacionar às mais distintas áreas de aplicação e se inter-relacionar entre as mesmas no que diz respeito ao desenvolvimento de novos produtos, especificamente na área de moda por intermédio do Design Têxtil e de Estamparia.

Desse modo, é possível concluir que por intermédio da estamparia têxtil, setor este diretamente relacionado ao Design de Superfície enquanto atrelado ao Design Têxtil, que a moda assume, assim, um papel comunicacional de grande importância no que diz respeito à promoção de um resgate de valores estético e histórico-funcionais através da estamparia ao reproduzir, de maneira direta, elementos da azulejaria portuguesa nas mais distintas peças de vestuário 
contemporâneas. A partir disso, torna-se possível afirmar que a azulejaria tem se tornado uma importante fonte não somente de inspiração, mas também direta ou indiretamente, um objeto de estudo e análise passível das mais diversas experimentações no campo do design enquanto inserida, especificamente, no desenvolvimento de produtos de moda por intermédio do Design Têxtil e de Estamparia.

\section{REFERÊNCIAS}

ALCÂNTARA, Dora de. Azulejos na cultura lusobrasileira. Rio de Janeiro: IPHAN, 1997.

AVELAR, Suzana. Moda, globalização e novas tecnologias. São Paulo: Estação das Letras e Cores Editora, 2009.

CASTILHO, Kathia; MARTINS, Marcelo M. Discursos da moda: semiótica, design e corpo. 2ed. rev. e atual. São Paulo: Editora Anhembi Morumbi, 2005. (Coleção moda e comunição/Kathia Castilho - Organização).

CHATAIGNIER, Gilda. Fio a Fio: tecidos, moda e linguagem. São Paulo: Estação das Letras Editora, 2006.

LASCHUK, Tatiana. Design Têxtil - da estrutura à superfície. Porto Alegre: Ed. UniRitter, 2009.

LIPOVETSKY, Gilles. O Império do Efêmero: moda e seu destino nas sociedades modernas. São Paulo: Companhia das Letras, 2009.

LOPES, Denilson. Somos todos Travestis: O Imaginário Camp e a Crise do Individualismo. Lugar Comum, Rio de Janeiro: NEPCOM/UFRJ, n. 9/10, p. 147-159, set. 1999/abr. 2000.

MORAIS, Frederico. Azulejaria Contemporânea no Brasil. São Paulo, Editoração Publicações e Comunicações, 1988.

PIRES, Dorotéia Baduy (org.). Design de Moda: olhares diversos. Barueri, SP: Estação das Letras e Cores Editora, 2008.

RUBIM, Renata. Desenhando a Superfície. São Paulo: Edições Rosari, 2005. 
RÜTHSCHILLING, Evelise Anicet. Design de Superfície. Rio Grande do Sul: UFRGS, 2008.

SoUZA, Jonas Soares de. Painéis de Azulejo do Museu Republicano "Convenção de Itu". São Paulo: Editora da Universidade de São Paulo/Museu Paulista, 2013.

YAMANE, Laura Ayako. Estamparia Têxtil. Dissertação de Mestrado apresentado ao Programa de Pós-Graduação Strictu Senso da Escola de Comunicação e Artes da Universidade de São Paulo. São Paulo, 2008. 